\title{
Performance evaluation of active wireline heave compensation systems in marine well logging environments
}

\author{
Tanzhuo Liu • Gerardo Iturrino • David Goldberg • \\ Eric Meissner - Kerry Swain • Clayton Furman • \\ Peter Fitzgerald • Nathan Frisbee • Joe Chlimoun • \\ John Van Hyfte • Ron Beyer
}

Received: 30 July 2012 / Accepted: 24 September 2012

(C) Springer-Verlag Berlin Heidelberg 2012

\begin{abstract}
The basic functionality and performance of a new Schlumberger active wireline heave compensation system on the JOIDES Resolution was evaluated during the sea trial and a 3-year period of the IODP Phase II operations. A suite of software programs was developed to enable real-time monitoring of the dynamics of logging tools, and assess the efficiency of wireline heave compensation during downhole operations. The evaluation of the system effectiveness was performed under normal logging conditions as well as during stationary tests. Logging data were analyzed for their overall quality and repeatability, and to assess the reliability of high-resolution data such as formation microscanner (FMS) electrical images. This revealed that the system reduces $65-80 \%$ of displacement or $88-98 \%$ variance of downhole tool motion in stationary mode under heave conditions of $\pm 0.2-1.5 \mathrm{~m}$ and water depths of $300-4,500 \mathrm{~m}$ in open holes. Under similar water/heave conditions, the compensator system reduces tool displacement by $50-60 \%$, or $75-84 \%$ variance in downhole tool motion during normal logging operations. Such compensation efficiency (CE) is comparable to previous compensation systems, but using advanced and upgradeable technologies, and provides 50 $85 \%$ heave motion and heave variance attenuation. Moreover,
\end{abstract}

T. Liu $(\bowtie) \cdot$ G. Iturrino $\cdot$ D. Goldberg $\cdot$ E. Meissner Borehole Research Group,

Lamont-Doherty Earth Observatory of Columbia University, Palisades, NY 10964, USA

e-mail: tanzhuo@1deo.columbia.edu

K. Swain $\cdot$ C. Furman $\cdot$ P. Fitzgerald $\cdot$ N. Frisbee

Schlumberger Technology Corporation,

P.O. Box 201193, Houston, TX 77216-1193, USA

J. Chlimoun · J. Van Hyfte $\cdot$ R. Beyer

Deep Down, Inc,

Houston, TX 77040, USA logging down/up at low speeds $(300-600 \mathrm{~m} / \mathrm{h})$ reduces the system's CE values by $15-20 \%$, and logging down at higher speeds $(1,000-1,200 \mathrm{~m} / \mathrm{h})$ eliminates $C E$ values by $55-65 \%$. Considering the high quality of the logging data collected, it is concluded that the new system can provide an improved level of compensation over previous systems. Also, if practically feasible, future integration of downhole cable dynamics as an input feedback into the current system could further improve its compensation efficiency during logging operations.

\section{Introduction}

In marine environments, floating platforms routinely encounter sea surface waves ranging from several $\mathrm{cm}$ to a few meters in height that generate both vertical heave and torsional ship motions. A wireline heave compensator is a critical onboard instrument that reduces downhole motion on logging tools deployed from a moving platform, and minimizes motion effects on downhole measurements (Goldberg 1990; Myers et al. 2001; Guerin and Goldberg 2002). During the Ocean Drilling Program (ODP) and the Integrated Ocean Drilling Program (IODP), LamontDoherty Earth Observatory (LDEO) of Columbia University, a partner in the US Implementing Organization (USIO), has been providing logging and downhole tool services aboard the JOIDES Resolution, a 143-m-long and 9,719ton seagoing research vessel that drills core samples and collects measurements below the seafloor (Fig. 1a). LDEO's Borehole Research Group designed and maintained a wireline heave compensating system that achieved efficient and high-quality logging data acquisition during ODP (19832003) and the IODP Phase I (2003-2005) operations (Goldberg 1990; Sarker et al. 2006; Guerin 2009). However, the LDEO system's configuration, its required maintenance, 
Fig. 1 a The JOIDES

Resolution deep-sea researchdrilling vessel showing the location of the heave compensating system (photo courtesy of USIO-IODP). b Sheave components of the DDI-AHC wireline heave compensator. c The hydraulic power unit and winch
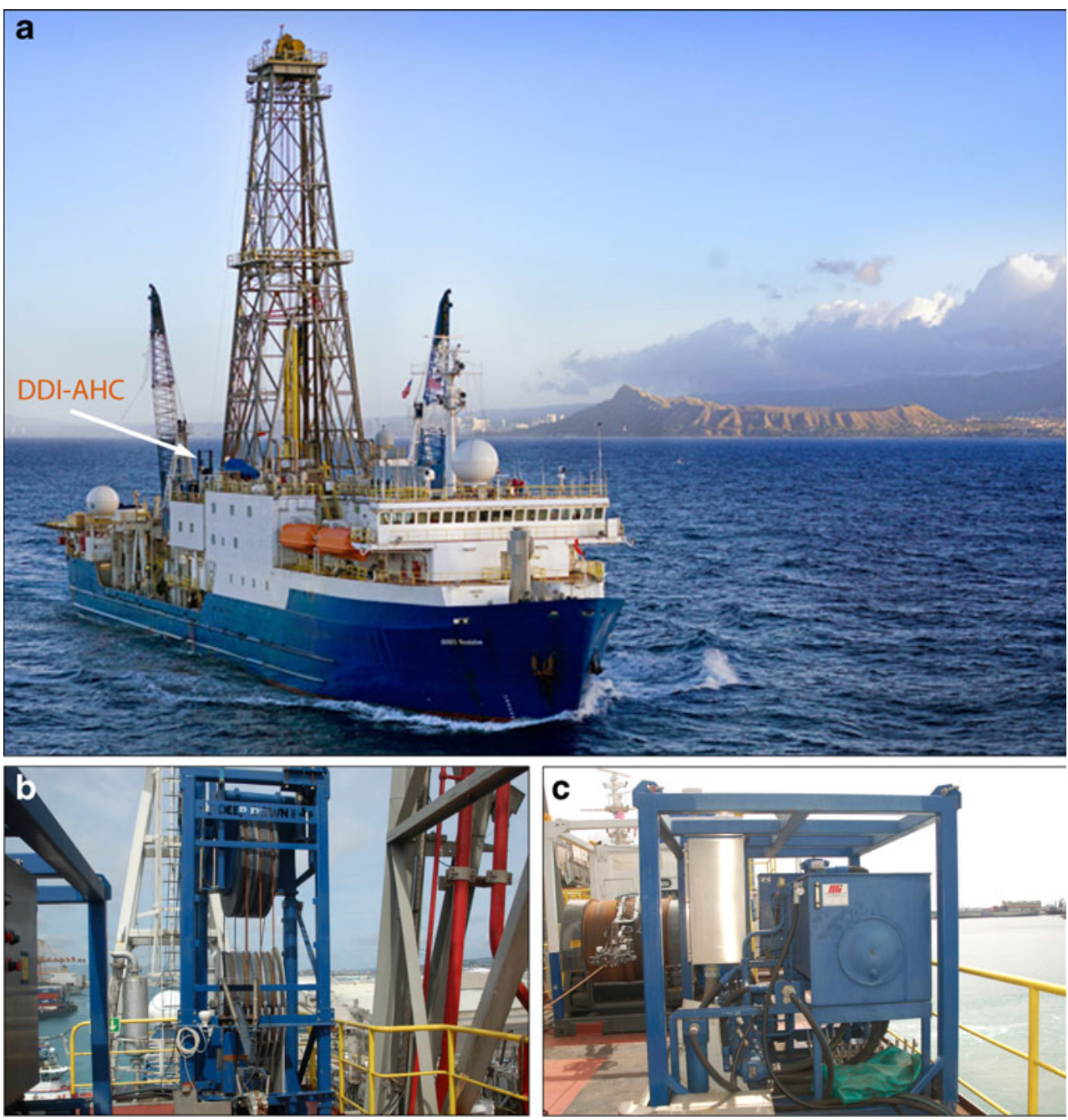

and its location away from the rig floor motivated the USIO to replace it with a more operationally flexible system that maintains or improves the compensation efficiency and data acquisition quality required by the scientific ocean drilling community. For IODP Phase II (2007-2013) operations, LDEO contracted Schlumberger, the USIO logging services subcontractor, to provide an active wireline heave compensator (AHC) on the JOIDES Resolution as part of the Scientific Ocean Drilling Vessel (SODV) project. Schlumberger commissioned Deep Down, Inc (DDI), a company based out of Houston for fabricating and delivering a system known as the DDI-AHC (Deep Down Inc-active heave compensator).

The purpose of this paper is twofold: (1) to present a quantitative assessment of the performance of the DDI-AHC in a well logging environment in varying water depths and sea states; and (2) to compare results from the DDI-AHC with previous compensation systems deployed during ODP and the IODP Phase I operations. The effects of logging variables such as water depth, sea state, logging direction and speed on the performance of the compensation system are also discussed.

\section{Heave compensation systems}

Early heave compensation systems and performance

The original LDEO wireline heave compensator (LWHC), sometimes also referred to as the heave motion compensator (HMC) or linear HMC, was designed and installed in 1986 on the ODP JOIDES Resolution. It was a horizontally oriented unit that used a hydraulic cylinder to move a piston and sheave that, like the DDI-AHC, paid out or retrieved logging cable according to acceleration-derived heave. The stroke piston's single sheave limited its stroke to $3 \mathrm{~m}$ and its ultimate heave compensation to $6 \mathrm{~m}$. By 2005, this unique system had been in service for nearly 20 years and thus considered unreliable for logging services during IODP Phase I operations. Schlumberger then installed and tested an innovative, prototype rotary smart wireline heave compensator (SWHC) as a replacement for the LWHC. Two reports were generated to assess its performance. Meltser (2005) claimed that the SWHC was more erratic but that its performance could improve with better input signal conditioning. Sarker et al. (2006) found 
that the SWHC compensated more effectively than the LWHC. However, it was determined during the early IODP Phase I operations that the SWHC was unable to compensate sufficiently to acquire high-resolution FMS images. As a result, LDEO elected to maintain the LWHC rather than pursue further development of the SWHC.

Sarker et al. (2006) compared the performance of the LWHC and SWHC, and reported that the LWHC performed consistently with a variety of logging tool strings. Results indicate that the LWHC reduced downhole tool displacement by more than $50 \%$, based on amplitudes of heaveinduced tool motion with the compensator turned on relative to when turned off, using fast Fourier transform (FFT) power amplitudes of surface and downhole acceleration data. The LWHC reduced variance of downhole tool motion by $52-74 \%$. For the SWHC, the authors reported $75-80 \%$ variance reduction in uphole heave versus downhole tool motion - an improvement over the LWHC and independent of water depth - and its mechanical and electrical systems performed reliably during the testing period. It should be noted, however, that heave conditions during both LWHC and SWHC tests were $\pm 1.8-2.5 \mathrm{~m}$, and that FFT analyses were performed using short time windows of only 512 to 1,024 data points. These factors may thus be considered to be too limited to qualify as representative tests of the performance of the systems.

The new Schlumberger DDI-AHC wireline heave compensation system

The DDI-AHC active wireline heave compensation system includes two primary components: the Proteus ${ }^{\mathrm{TM}}$ compensator unit, and its hydraulic power unit (HPU). These operate together with the Schlumberger winch and winch cab, and form the ship's complete wireline logging heave-compensating system (Fig. 1b, c). The Proteus unit is a ram-type compensator that uses a set of sheaves mounted in an overhead flying head that moves vertically in opposition to the direction of vessel motion. The sheave assembly contains six active cable legs that reduce the required compensator stroke by $6: 1$. The flying head moves up and down relative to its fixed base, using two hydraulic cylinders that are plumbed to the HPU such that the rod and blind ends are tied together. A pump supplies hydraulic fluid to a high-performance Vickers/Eaton servo valve, which either forces fluid into the cylinders or routes it into a reservoir. The valve operates on electrical signals that come from the control system. The position of the flying head is measured using a linear position transducer consisting of an external sensor and a dynamic magnet.

The control system uses vessel motion information acquired from an accelerometer package or motion reference unit (MRU) to control the servo valve, thereby positioning the flying sheave at the desired location. Drift in accelerometer data is automatically minimized by the MRU. The DDI-AHC MRU is located close to the ship's center of rotation. A ball valve locks the system into its lowest position when not in use. When the ball valve is opened and active heave compensation is initiated, the control system moves the flying sheave in synchronization with the vessel and maintains the desired motion/compensator relation. Commercial software enables the system to connect, diagnose, and manipulate the tuning parameters of the DDI-AHC. Detailed technical specifications of the system are given in Table 1, and the rig floor configuration of the system is shown in Fig. 2.

\section{Performance evaluation of the DDI-AHC}

\section{Definition of compensation efficiency}

The effectiveness of a heave compensation system can be measured by the rms (root mean square) reduction ratio of a compensated signal and an original signal (Driscoll et al. 2000). In the present study, the rms reduction ratio of downhole displacement versus surface heave was chosen because it provides a direct average measure of compensated motion of the tool string over a given period of time. In the time domain, the compensation efficiency (CE-std) can thus be defined as

CE-std $=[1-\operatorname{std}(d d) / \operatorname{std}(h h)] \times 100$

where $d d$ is the downhole displacement of the tool string, $h h$ the uphole (surface) heave of the vessel, and std the standard deviation. Both uphole heave and downhole displacements are calculated by double integration of the corresponding acceleration data.

In the frequency domain, the compensation efficiency CE-fft is often defined as

$$
\begin{aligned}
\text { CE-fft }= & {[1-\operatorname{PowerFFT}(a d) / \operatorname{PowerFFT}(a u)] } \\
& \times 100
\end{aligned}
$$

where $a u$ is the uphole acceleration of the ship, ad the downhole acceleration of the tool string, and PowerFFT the power amplitude of fast Fourier transform (FFT) of the uphole and downhole accelerations.

In order to compare the CEs calculated in the present study with those reported for previous wireline heave compensation systems, CE-var was also calculated, defined as

$$
\mathrm{CE}-\operatorname{var}=[1-\operatorname{var}(d d) / \operatorname{var}(h h)] \times 100
$$

or

CE-var $=\left[1-(1-\text { CE-std })^{2}\right] \times 100$

where var stands for variance. 
Table 1 Technical specifications of the Schlumberger DDI-AHC heave compensator (data source: Deep Down, Inc (www.deepdowncorp.com/ deepdown)

\section{Specification}

Tension capacity

Heave compensation

Heave accuracy

Heave period

Working load

Features
$12,000 \mathrm{lbs}$

$9.3 \mathrm{~m}$ total heave (4.15 m movement from center up and down)

\pm 0.5 inches in 30 feet seas (theoretical accuracy); \pm 3 inches in 30 feet seas (worst-case accuracy)

Designed to maintain vertical displacement of a subsea payload to within six-tenths of an inch even if the surface ship is experiencing a heave of up to 30 feet

20 -second tested period, smaller heaves can be much faster

7,500 to $15,000 \mathrm{lbs}$

Re-programmable controller for different operation/environmental conditions

High-performance proportional valve (important for particular rejection)

Based on GPS and on-board heave sensors

Line tension measurements provided by an in-line tension measurement sensor

Allen-Bradley PLC and a MRU sensor derives vessel heave data and translates the data into valve control signals to drive the hydraulic actuators
In practice, the relative compensation efficiency (RCE) is often used to characterize the relative reduction in magnitude of downhole tool motion when the compensator is "on" versus when it is "off", defined as

$$
\mathrm{RCE}-\mathrm{std}=\left[1-\operatorname{std}(d d)_{\mathrm{WHC}-\mathrm{on}} / \operatorname{std}(d d)_{\mathrm{WHC}-\mathrm{off}}\right] \times 100
$$

$$
\operatorname{RCE}-\operatorname{var}=\left[1-\operatorname{var}(d d)_{\mathrm{WHC}-\mathrm{on}} / \operatorname{var}(d d)_{\mathrm{WHC}-\mathrm{off}}\right] \times 100
$$

$$
\mathrm{RCE}-\mathrm{fft}=\left[1-\text { PowerFFT }(a d)_{\mathrm{WHC}-\mathrm{on}}\right.
$$

$$
\left./ \text { PowerFFT }(a d)_{\mathrm{WHC}-\text { off }}\right] \times 100
$$

It should be noted that CE-std by definition measures $\mathrm{CE}$ in terms of the standard deviation or rms of calculated displacement, while CE-var measures $\mathrm{CE}$ in terms of the variance of calculated displacement, and $\mathrm{CE}-\mathrm{fft}$ measures $\mathrm{CE}$ in terms of the FFT power amplitude of input accelerations. Because both CE-var and CE-fft are calculated on the basis of power (or variance) of the input signals, they should be similar for any given $\mathrm{CE}$.

\section{Data acquisition and CE evaluation}

In order to assess the performance of the DDI-AHC system while operating on the JOIDES Resolution, a suite of software programs was developed at LDEO to enable real-time monitoring of the dynamics of the logging tools and assess the efficiency of the heave compensation (Fig. 3). Downhole acceleration data are acquired using Schlumberger's general purpose inclinometer tool (GPIT). Designed to measure borehole inclination, it includes a three-axis accelerometer package. The z-axis accelerometer measures along the tool's long axis, which in most IODP boreholes is vertical. During logging operations, $120 \mathrm{~Hz}$ z-axis acceleration data are sent uphole to the Schlumberger surface acquisition computer (MCM). In order to use the GPIT acceleration data in real-time performance evaluation of the system, LDEO and Schlumberger have modified the acquisition

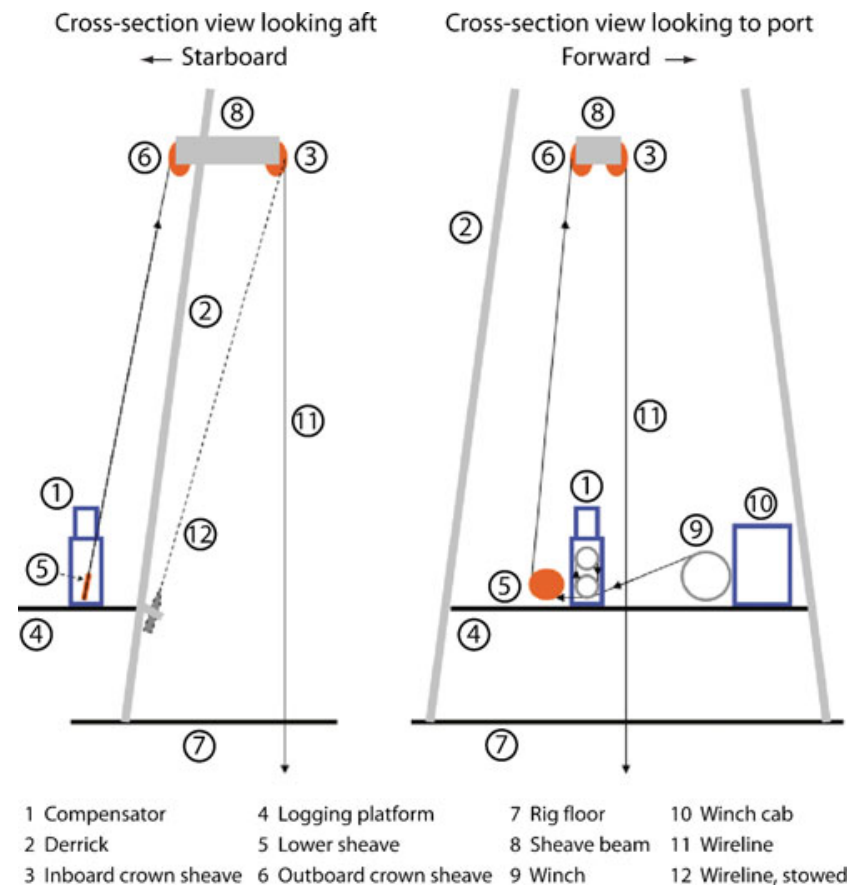

Fig. 2 Aft- and port-facing cross-section views of the Schlumberger DDI-AHC heave compensator and logging systems 


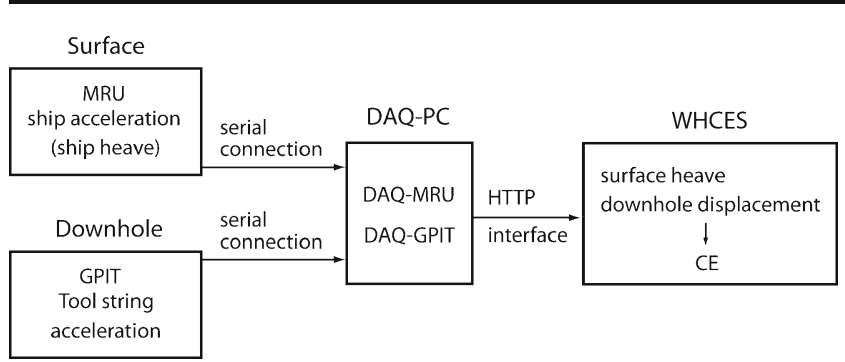

Fig. 3 Diagram showing the configuration and data flow of surface heave and downhole tool motion data acquisition and heave compensation assessment systems

software to enable real-time streaming output of resampled $(15 \mathrm{~Hz})$ downhole acceleration data. The GPIT data are streamed out of the MCM via a serial port connected to the LDEO data acquisition computer (DAQ-PC). The MCM and DAQ-PC clocks are synchronized to a shipboard timeserver and the surface acceleration data are acquired by a dedicated MRU, which uses its accelerometers to calculate heave. Acceleration and heave data are streamed at $30 \mathrm{~Hz}$ out from a serial port ultimately connected to the DAQ-PC.

The DAQ-PC has two Labview utilities, DAQ-MRU and DAQ-GPIT, which take the MRU and GPIT streamed inputs. Each utility appends a UNIX timestamp to its respective data. A Matlab program developed by LDEO's Borehole Research Group, called the wireline heave compensation evaluation system (WHCES), is used to access GPIT and MRU data approx. every $5 \mathrm{~s}$ via an HTTP interface for real-time CE calculation and display. The WHCES system is synchronized to the DAQ-PC and MCM.

\section{Data quality}

To assess whether the GPIT-derived displacement data represent the true values of the downhole tool motion, the GPIT-equipped Triple Combo tool string was lowered to $9.7 \mathrm{~m}$ below rig floor (mbrf) so that the GPIT would be at the same level as the MRU for 5-15 minutes of data collection before each stationary test and logging operation. Because both GPIT and MRU measure the same acceleration of the ship in this position, their acceleration readings and acceleration-derived heave measurements can be calibrated to equal in magnitude and phase values. Figure 4 shows that the heaves of the ship calculated by MRU (heave-mru) and by GPIT (heave-gpit) from MRU and GPIT acceleration data are in excellent agreement. The standard deviation of heave-gpit versus that of heave-mru is 1.04. In other words, their standard deviations are within $5 \%$ of their measurement uncertainties. This result indicates that both acceleration and displacement data are accurate and of high quality. Below, both MRU and GPIT measurements have been used for real-time $\mathrm{CE}$ evaluation of the DDI-AHC heave compensator.
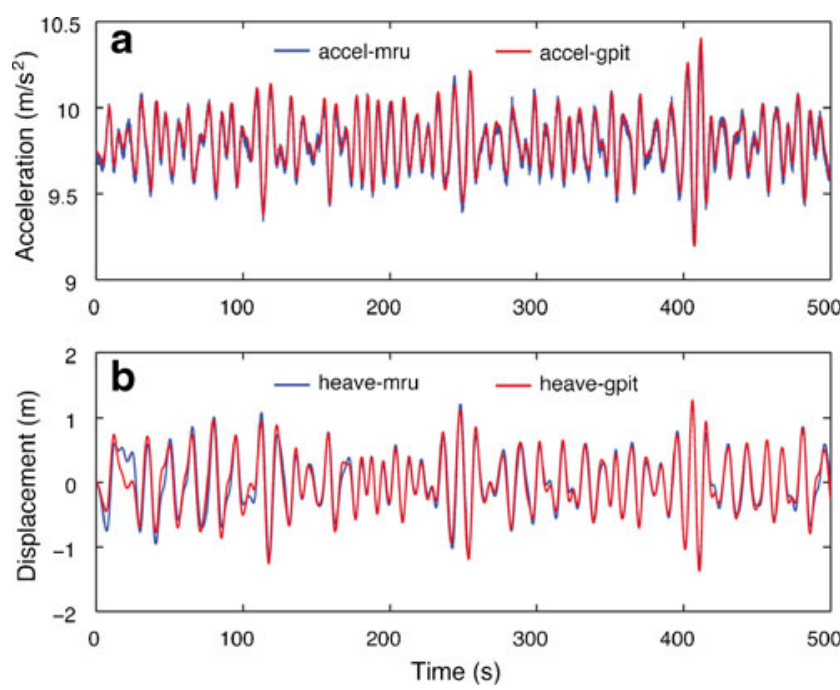

Fig. 4 a Comparison of acceleration data collected by MRU (accelmru) and by GPIT (accel-gpit). Both MRU and GPIT were placed at $9.7 \mathrm{~m}$ below rig floor and they should record the same acceleration of the ship, as shown in the figure. $\mathbf{b}$ Comparison of heave data calculated by MRU (heave-mru) and using WHCES (heave-gpit). The heave data thereby derived are identical within $5 \%$ measurement uncertainty

\section{Results}

The performance assessment of the DDI-AHC consisted of three parts: (1) computation of the CE of the system when the tool string was stationary, positioned at different depths in the drill pipe, and/or in open hole. During each stationary test, the logging tool was positioned at a pre-determined depth, and then uphole and downhole acceleration data were collected with and without the DDI-AHC. (2) Evaluation of dynamic $\mathrm{CE}$ in open hole, while logging up or down at different speeds and with different tool strings. During each dynamic test, the DDI-AHC remained activated for the entire logging operation, both uphole and downhole acceleration data being continuously collected. Real-time CE evaluation and display of the DDI-AHC data was computed using the WHCES. (3) Qualitative analysis of DDI-AHC performance by evaluation of field logging data.

The following performance analyses are based on data from CE results obtained during the sea trials in 2009 (IODP Expedition 320T) and subsequent IODP Phase II expeditions (335-340), as summarized in Table 2.

\section{Stationary test results}

Figure 5 shows a typical real-time $\mathrm{CE}$ evaluation and display by the WHCES for the duration of a stationary test during the sea trial. For most of the test period $(\mathrm{ET}=0$ 70 minutes), the DDI-AHC performed within a CE-std range of 20-40\% before it was tuned for optimum performance. Negative values (CE-std of -20 to $-40 \%$ ) were recorded at $\mathrm{ET}=38$ minutes when the system was turned 
Table 2 Stationary and dynamic test results of the Schlumberger DDI-AHC heave compensator ${ }^{\mathrm{a}}$

\begin{tabular}{|c|c|c|c|c|c|c|c|c|c|c|c|c|c|}
\hline $\begin{array}{l}\text { Expedition/ } \\
\text { hole }\end{array}$ & $\begin{array}{l}\text { Tool } \\
\text { string }^{b}\end{array}$ & $\begin{array}{l}\text { Water } \\
\text { depth } \\
\text { (mbrf) }\end{array}$ & $\begin{array}{l}\text { Test } \\
\text { depth } \\
\text { (mbrf) }\end{array}$ & $\begin{array}{l}\text { Max } \\
\text { heave } \\
( \pm \mathrm{m})\end{array}$ & $\begin{array}{l}\text { Heave } \\
\text { period } \\
\text { (s) }\end{array}$ & $\begin{array}{l}\text { Test } \\
\text { duration } \\
\text { (s) }\end{array}$ & $\begin{array}{l}\text { Logging } \\
\text { speed } \\
(\mathrm{m} / \mathrm{h})\end{array}$ & $\begin{array}{l}\text { Max } \\
\text { CE-std } \\
(\%)\end{array}$ & $\begin{array}{l}\text { Max } \\
\text { CE-var } \\
(\%)\end{array}$ & $\begin{array}{l}\text { Mean } \\
\text { CE-std } \\
(\%)\end{array}$ & $\begin{array}{l}\text { Mean } \\
\text { CE-var } \\
(\%)\end{array}$ & $\begin{array}{l}\text { Mean } \\
\text { CE-fft } \\
(\%)\end{array}$ & Figs. \\
\hline \multicolumn{14}{|l|}{ Stationary test } \\
\hline 320T/U1330A & $\mathrm{TC}$ & 2,896 & $300^{\mathrm{d}}$ & $1.0-1.5$ & 8 & 600 & 0 & 74 & 93 & 65 & 88 & 85 & $6 b$ \\
\hline 339/U1386C & $\mathrm{TC}$ & 575 & 743 & $0.1-0.2$ & 11 & 360 & 0 & 86 & 98 & 80 & 96 & 96 & 7 \\
\hline 339/U1389A & $\mathrm{TC}$ & 575 & 810 & $0.2-0.4$ & 7 & 404 & 0 & 76 & 94 & 68 & 90 & 87 & $6 a$ \\
\hline 335/U1259D & $\mathrm{TC}$ & 3,643 & 4,000 & $0.5-1.0$ & 10 & 180 & 0 & 70 & 91 & 64 & 87 & 90 & \\
\hline 336/U1383C & $\mathrm{TC}$ & 4,494 & 4,590 & $0.5-1.0$ & 13 & 300 & 0 & 82 & 97 & 75 & 94 & 96 & $6 c$ \\
\hline \multicolumn{14}{|l|}{ Dynamic test } \\
\hline \multirow[t]{2}{*}{ 339/U1389A } & $\mathrm{TC}$ & 575 & 1,012 & $0.2-0.4$ & 7 & 2,800 & 300 (up) & 68 & 90 & 54 & 79 & 69 & \\
\hline & FMS & 575 & 1,010 & $0.2-0.4$ & 14 & 1,435 & 600 (up) & 71 & 92 & 60 & 84 & 93 & $9 \mathrm{a}$ \\
\hline \multirow[t]{2}{*}{ 339/U1391C } & $\mathrm{TC}$ & 575 & 1,754 & $0.5-0.8$ & 14 & 6,300 & 300 (up) & 69 & 90 & 53 & 78 & 82 & \\
\hline & FMS & 575 & 1,754 & $0.5-0.8$ & 14 & 3,200 & 600 (up) & 85 & 98 & 56 & 80 & 87 & $9 b$ \\
\hline \multirow[t]{2}{*}{ 340T/U1309D } & $\mathrm{TC}$ & 1,656 & 2,419 & $0.5-1.0$ & 9 & 725 & 1,600 (up) & 68 & 90 & 59 & 83 & 88 & \\
\hline & & & 2,165 & $0.5-1.0$ & 9 & 2,400 & 500 (up) & 69 & 90 & 58 & 83 & 86 & $9 \mathrm{c}$ \\
\hline \multicolumn{14}{|c|}{ Logging speed effect ${ }^{\mathrm{c}}$} \\
\hline \multirow[t]{2}{*}{ 339/U1386C } & $\mathrm{TC}$ & 575 & 743 & $0.1-0.2$ & 8 & 1,350 & $1,200(\mathrm{dw})$ & & & 13 & 25 & & \\
\hline & & & 743 & $0.1-0.2$ & 9 & 700 & 300 (up) & & & 48 & 73 & & \\
\hline \multirow[t]{2}{*}{ 339/U1389E } & FMS & 575 & 1,220 & $0.2-0.4$ & 11 & 1,490 & $1,000(\mathrm{dw})$ & & & 11 & 20 & & \\
\hline & & & 830 & $0.2-0.4$ & 11 & 800 & 600 (up) & & & 39 & 63 & & \\
\hline \multirow[t]{3}{*}{ 340/U1395B } & $\mathrm{TC}$ & 1,209 & 1,175 & $0.3-0.5$ & 8 & 330 & $600(\mathrm{dw})$ & & & 40 & 64 & & 8 \\
\hline & & & 1,412 & $0.3-0.5$ & 9 & 860 & 300 (up) & & & 46 & 70 & & 8 \\
\hline & & & 1,412 & $0.3-0.5$ & 8 & 1,200 & 300 (up) & & & 42 & 67 & & 8 \\
\hline
\end{tabular}

${ }^{a}$ The data reported here are the best CE results from each test session after the heave compensator was tuned to its optimum performance level

${ }^{\mathrm{b}}$ Two types of tool strings were used during the tests: Triple Combo (TC) and FMS. The TC tool string is about $25-30 \mathrm{~m}$ long and weighs about 2,100 lbs (or 1,600 lbs in fluid). The FMS tool string is about 25-30 m long and weighs about 1,600 lbs (or 1,235 lbs in fluid). Both TC and FMS have caliper arms that stretched out against the borehole wall while logging up, but were closed up during stationary tests or down logging. The logging cable used is about $1,090 \mathrm{lbs} / \mathrm{km}$ (or $828 \mathrm{lbs} / \mathrm{km}$ in fluid)

${ }^{\mathrm{c}}$ For those dynamic tests on logging speed effects, the CE-std and CE-var values were calculated for selected time intervals that likely represent the overall characteristics of each logging session. Other CEs such as Max CE-std and CE-fft were not calculated due to their large variations

${ }^{d}$ Although the water depth at this test site was $2,896 \mathrm{mbrf}$, the tool string was stationed at $300 \mathrm{mbrf}$ within the drill pipe during the test. Hence, the "300 mbrf" at this test site represents an "equivalent water depth" for the stationary test

off for a quick adjustment of tuning parameters. The maximum downhole displacement during this short "DDI-AHC off" period jumped from $\pm 0.6 \mathrm{~m}$ to its peak value of $\pm 1.65 \mathrm{~m}$ while the maximum heave remained $\pm 1.2 \mathrm{~m}$, indicating RCE-std $=64 \%$ or RCE-var $=87 \%$. During the test period of ET $=73-88$ minutes, the system reached its best performance level with a maximum CE-std of $68 \%$ and a mean CE-std of $52 \%$, while the compensated downhole displacement decreased to its lowest level of $\pm 0.4-0.5 \mathrm{~m}$ at maximum heave of $\pm 1.3 \mathrm{~m}$. At the end of the test (ET= 88-90 minutes), the CE-std dropped to between -20 and $-40 \%$ after the compensator was turned off. The relative CE calculated from the FFT power amplitude of downhole tool acceleration (RCE-fft) is $86 \%$, very similar to RCE-var $=87 \%$ converted from RCE-std $=64 \%$.

Figure 6 depicts the best $\mathrm{CE}$ results obtained during the stationary tests under varying water and sea conditions. In shallow water (575 mbrf) with low heave $( \pm 0.2-0.4 \mathrm{~m})$, the system was able to reduce displacement by $68 \%$, or $90 \%$ variance of the tool motion. Compensated downhole displacement is less than $\pm 0.1 \mathrm{~m}$ (Fig. 6a). In shallow water (300 mbrf) with moderate heave $( \pm 1.0-1.5 \mathrm{~m})$, the system was able to reduce displacement by $65 \%$, or $88 \%$ variance of the tool motion with compensated downhole displacement of $\pm 0.3-0.4 \mathrm{~m}$ (Fig. 6b). Without heave compensation, the downhole displacement increases to $\pm 1.3 \mathrm{~m}$, indicating RCE-std $=75 \%$ or RCE-var $=94 \%$. In deep water $(4,590 \mathrm{mbrf})$ with low heave $( \pm 0.5-1.0 \mathrm{~m})$, the system reduces displacement by $75 \%$, or $94 \%$ variance of the tool motion, and the compensated downhole displacement is $\pm 0.2-0.3 \mathrm{~m}$ (Fig. 6c).

Figure 7 illustrates the highest compensation efficiency of CE-std $=80 \%$ or CE-var $=96 \%$ ever obtained by the DDI-AHC during the stationary tests, with the maximum 
Fig. 5 Real-time CE-std evaluation and display of the Schlumberger DDI-AHC heave compensator with the tool string stationed at $300 \mathrm{mbrf}$ in the drill pipe during the sea trials
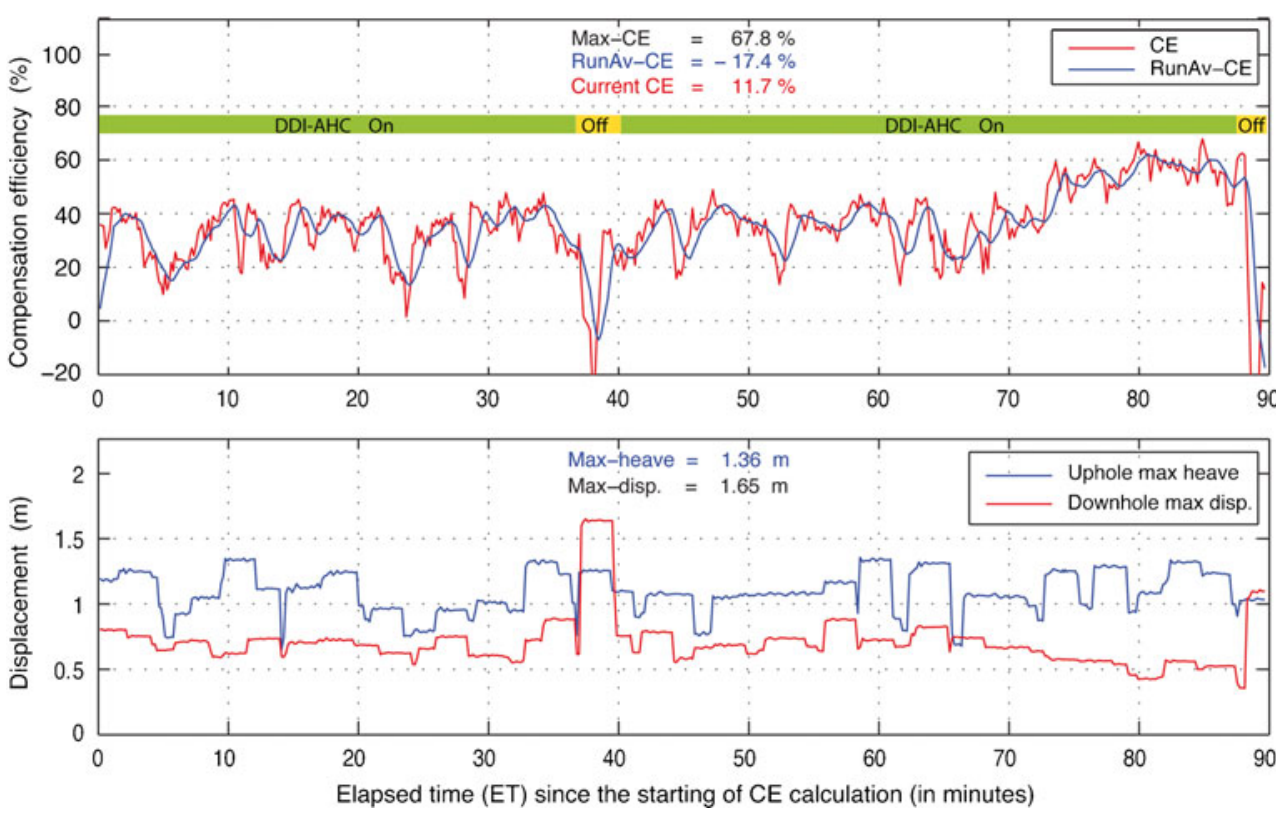

instant CE-std ${ }_{\text {ins }}=86 \%$ or CE-var ${ }_{\text {ins }}=98 \%$ (Table 2$)$. In a water depth of $573 \mathrm{mbrf}$ (testing depth of $775 \mathrm{mbrf}$ ) and with a low heave of $\pm 0.15 \mathrm{~m}$, the compensator was able to reduce downhole tool motion to less than $\pm 0.03 \mathrm{~m}$. Although such high CE performance lasted approx. 6 minutes during the test, it indeed demonstrates the full capability and high CE potential of the DDI-AHC compensation system in a borehole environment.
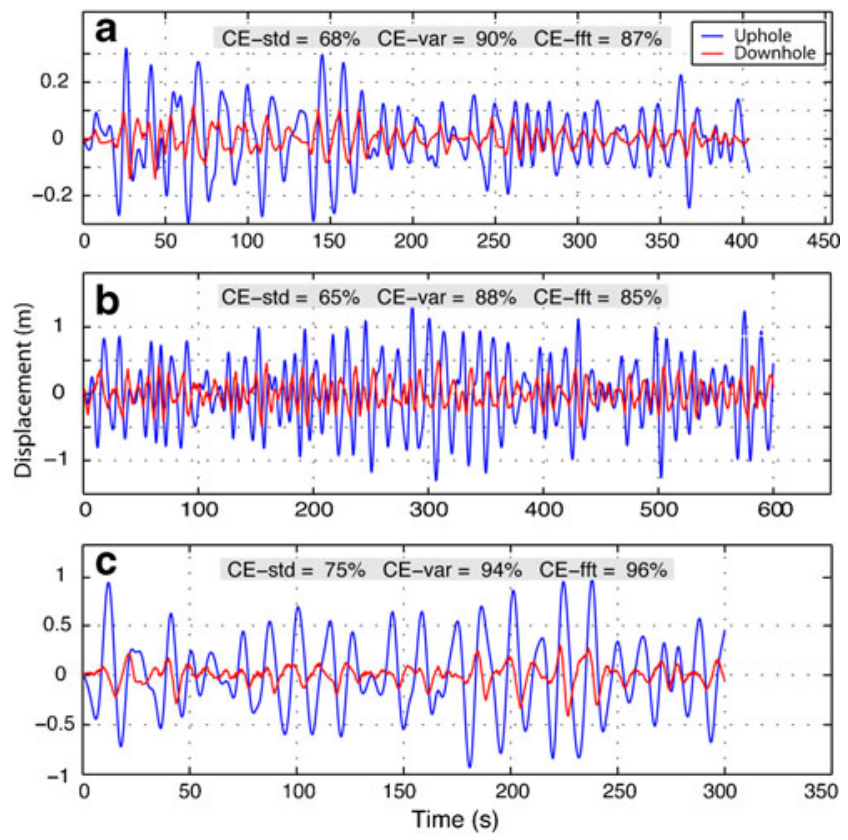

Fig. 6 Best CE-std performances of the Schlumberger DDI-AHC heave compensator in varying water depths and sea states during stationary tests. a Shallow water $(575 \mathrm{mbrf})$ and low heave $( \pm 0.2-$ $0.4 \mathrm{~m})$; b shallow water (300 mbrf) and moderate heave $( \pm 1-1.5 \mathrm{~m})$; c deep water $(4,494 \mathrm{mbrf})$ and low heave $( \pm 0.5-1 \mathrm{~m})$
In summary, the stationary tests indicate that, regardless of water depth and heave, the DDI-AHC performed in a CEstd range of $65-80 \%$, or a CE-var range of $88-96 \%$ in the borehole environment, with a maximum CE-std ${ }_{\text {ins }}$ of $86 \%$, or CE-varins of $98 \%$.

Dynamic test results

Figure 8 shows a typical real-time CE evaluation and display by the WHCES during deployment of a Triple Combo tool string during IODP Expedition 340, hole U1395B, in a water depth of $1,209 \mathrm{mbrf}$ and heave of $\pm 0.3-0.6 \mathrm{~m}$. During
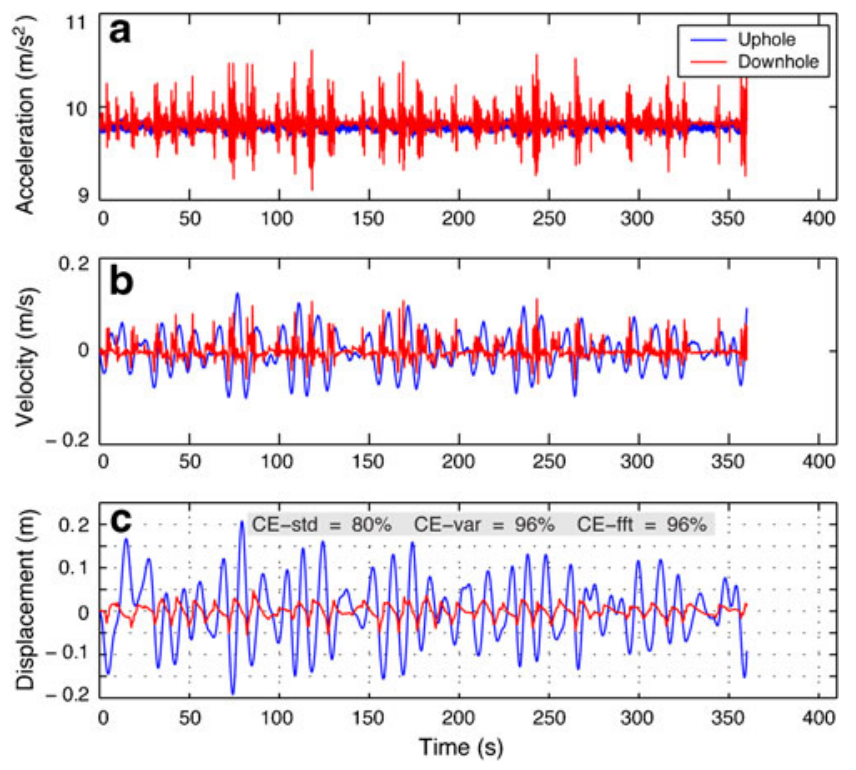

Fig. 7 The highest CE-std performance attained by the Schlumberger DDI-AHC heave compensator during the stationary tests in shallow water (575 mbrf) and low heave $( \pm 0.1-0.2 \mathrm{~m})$ 
Fig. 8 Real-time CE-std evaluation and display of the Schlumberger DDI-AHC heave compensator during deployment of the Triple Combo tool string at IODP Exp 340 hole U1395B in intermediate water $(1,209 \mathrm{mbrf})$ and low heave $( \pm 0.3-0.5 \mathrm{~m})$
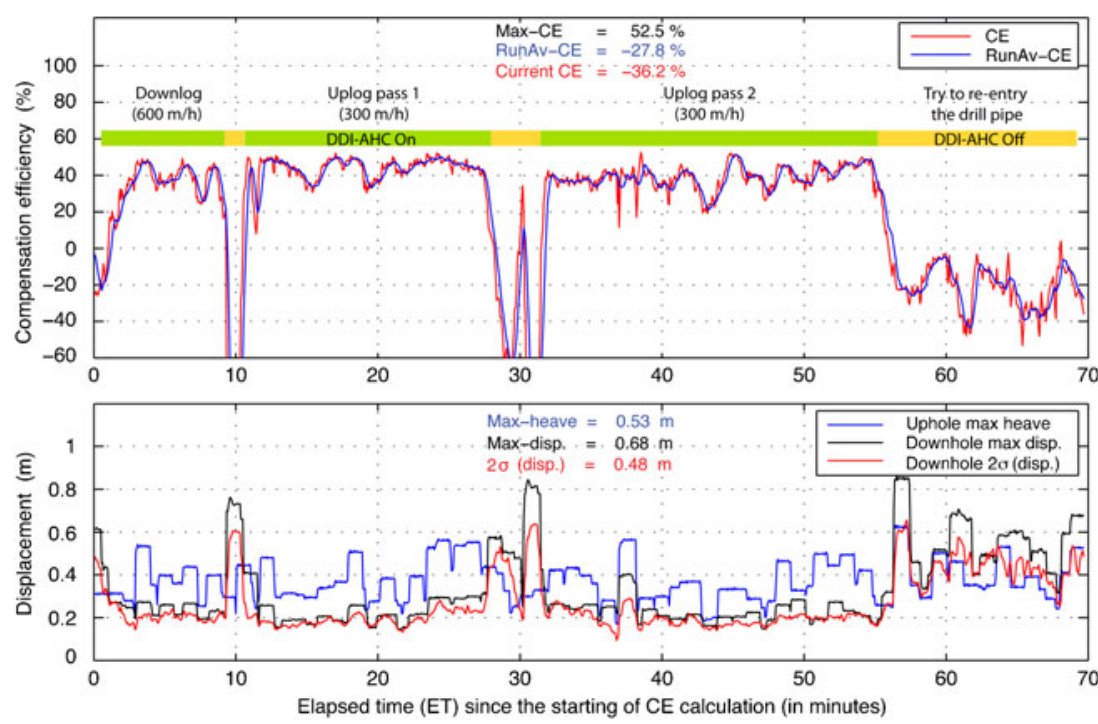

the first down $\log (E T=1-10$ minutes $)$, the logging speed was $600 \mathrm{~m} / \mathrm{h}$ and the DDI-AHC performed in a CE-std range of $30-50 \%$, with a mean CE-std of $40 \%$. During the subsequent up logs $(\mathrm{ET}=10-27$ minutes and $\mathrm{ET}=32-$ 55 minutes), the logging speed was $300 \mathrm{~m} / \mathrm{h}$ and the DDIAHC performed in a CE-std range of 35-50\%, with a mean CE-std of $46 \%$ for $\log$ pass 1 and $42 \%$ for $\log$ pass 2 . Two sharp drops in CE-std $(<-60 \%)$ before and after log pass 1 were caused by the temporary shutdown of the DDI-AHC. As a result, the downhole displacement of the tool string jumped from $\pm 0.2 \mathrm{~m}$ to $\pm 0.6 \mathrm{~m}$ while the ship heave remained the same $( \pm 0.3-0.5 \mathrm{~m})$, indicating an RCE-std of $67 \%$, or RCE-var of $90 \%$. At the end of the $\log (\mathrm{ET}=55-70$ minutes), the CE-std decreased to between -20 and $-40 \%$ after the DDI-AHC was turned off. The relative CE from the FFT power amplitude of downhole tool acceleration is RCE-fft $=88 \%$, which is very close to RCE-var $=90 \%$.

Figure 9 presents the best real-time CE results obtained during logging operations in varying water depths and sea states. Triple Combo and FMS tool strings were deployed at logging speeds of $300-600 \mathrm{~m} / \mathrm{h}$ in shallow water ( $575 \mathrm{mbrf}$ ) with low heave $( \pm 0.2-0.4 \mathrm{~m})$. The DDI-AHC reduced displacement by $60 \%$ or $84 \%$ variance of the downhole tool motion (Fig. 9a). In shallow water (575 mbrf) with slightly higher heave $( \pm 0.5-0.8 \mathrm{~m})$, the system was able to reduce downhole displacement by $56 \%$, equivalent to $80 \%$ downhole variance (Fig. 9b). In intermediate water (1,656 mbrf) with relatively low heave $( \pm 0.5-1.0 \mathrm{~m})$, the system reduced displacement by $58 \%$, or $83 \%$ of downhole variance (Fig. 9c).

Overall, there appears to be a 15-20\% decrease in CE values during the logging operations compared to stationary tests. During the stationary tests, the DDI-AHC performed at an average CE-std range of $65-80 \%$, whereas during the logging operations with normal logging speeds (300-600 m/ h) the system performed at an average CE-std range of 50$60 \%$. This reduction in $\mathrm{CE}$ is attributed to the upward or downward motion of the tool string while logging (see Table 2 and the Discussion section for further details).

In summary, the dynamic test results indicate that, regardless of water depth and heave, the DDI-AHC performed in a CE-std range of 53-60\%, or a CE-var range of 78$84 \%$ during logging operations, with a maximum CE-std ${ }_{\text {ins }}$ of $85 \%$, or CE-varins of $98 \%$ (Table 2 ).

Qualitative analysis using logging data

Ultimately, heave compensation efficiency determines the quality of the recorded logging data. Therefore, assessing log data quality can provide a qualitative analysis of the DDI-AHC performance. Under a given borehole condition, the FMS data quality is largely controlled by the variations in the speed of the tool, which must be corrected during the FMS image processing through downhole depth shift correction calculated using acceleration data provided by the GPIT. Such depth corrections can therefore be used as a representative measure to evaluate the effectiveness of the heave compensation during logging operations.

During the sea trials, the FMS tool string (HNGS-GPITFMS) was deployed in hole U1330A to test the depth control of the DDI-AHC wireline heave compensation system while recording high-resolution electrical images. The hole was drilled to a target depth of $550 \mathrm{mbsf}$ with limited coring from 103.6-122.81 mbsf in order to minimize hole damage due to the coring process. This resulted in good hole conditions, the hole size remaining fairly uniform from TD (total depth) to $350 \mathrm{mbsf}$, before gradually increasing uphole to $250 \mathrm{mbsf}$, above which the caliper is in poor contact with the formation. Hole conditions in U1330A, therefore, are of good quality throughout most of the hole, enabling reliable evaluation of FMS data quality. 
Fig. 9 Best CE-std performances of the Schlumberger DDIAHC heave compensator in varying water depths and sea states during the dynamic tests. a Shallow water ( $575 \mathrm{mbrf})$ and low heave $( \pm 0.2-0.4 \mathrm{~m})$; b shallow water ( $575 \mathrm{mbrf}$ ) and low heave $( \pm 0.5-0.8 \mathrm{~m})$; $\mathbf{c}$ intermediate water $(1,656 \mathrm{mbrf})$ and low heave $( \pm 0.5-1 \mathrm{~m})$
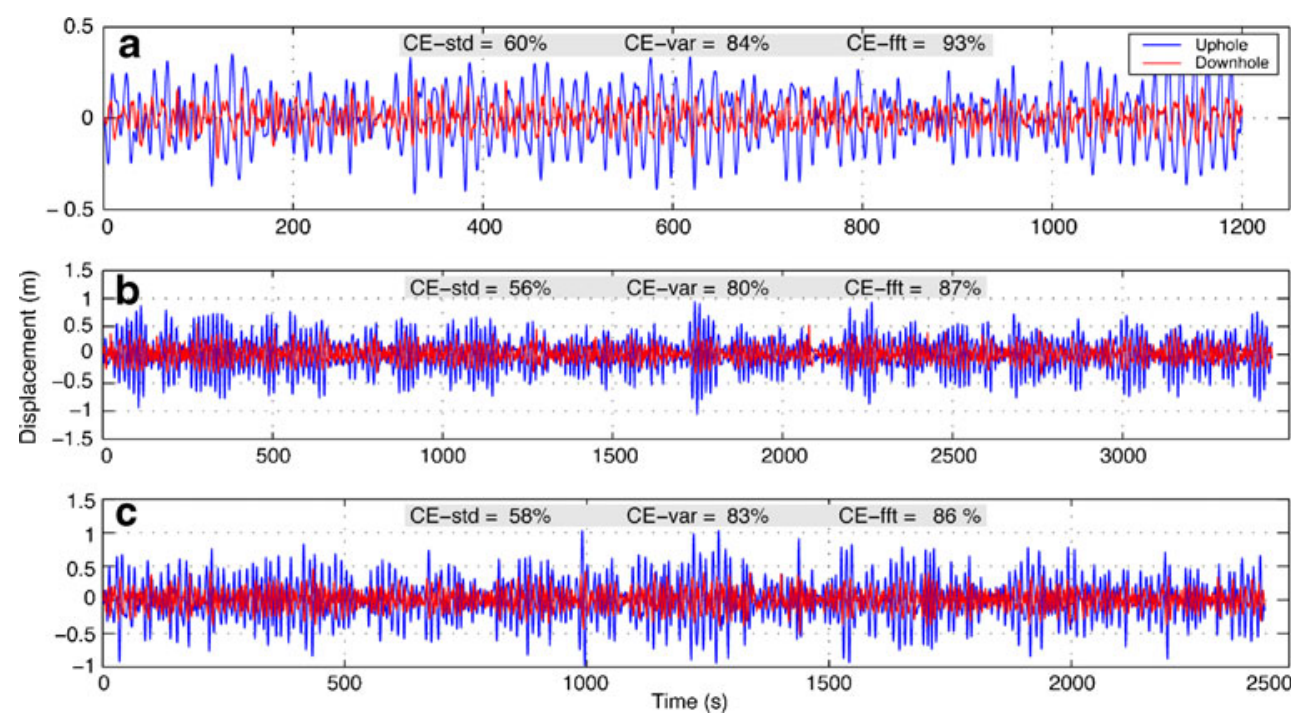

Figure 10 shows a comparison between the downhole depth shifts applied over a 50-m section of FMS data recorded in hole 1328C during IODP Expedition 311 using the SWMC, and those over a 100-m section derived in hole U1330A using the DDI-AHC. The overall similarity between the two holes suggests effective heave compensation by both systems, although the corrections applied in hole 1330A show smoother variation (mean standard deviation of $0.265 \mathrm{~m}$ ) than in hole $1328 \mathrm{C}$ (mean standard deviation of $0.275 \mathrm{~m}$ ). This may be closely related to the heave magnitude, and suggests that the DDI-AHC not only compensates surface motion at a level similar to the previous system, but that these depth corrections are more favorable for FMS image correction. In addition, the lower amplitude of the depth corrections for tool motion during the second pass than during the first in hole U1330A confirms the higher efficiency of heave compensation measured during pass 2 .

Finally, Fig. 11 presents two examples of intervals in hole U1330A where distinct features can be seen in the FMS images over the lower section of the hole (passes 1 and 2 shown side by side for comparison). Resistive horizontal layers (bright) indicate thin bedding (Fig. 11a), whereas sinusoidal patterns indicate dipping beds (Fig. 11b). Note that the depth offsets for individual features between the two passes do not exceed $0.5 \mathrm{~m}$, and each distinctive structure is reproduced with the same sharpness during the two passes. Such repeatability results from depth control and the effectiveness of the wireline heave compensator.

\section{Discussion}

Performance evaluation of the DDI-AHC system

Based on the analyses of the test data collected in drill pipe and open holes, it was found that the DDI-AHC reduces displacement by $65-80 \%$, or $88-96 \%$ variance of downhole tool motion in a stationary mode for heave of \pm 0.2 $1.5 \mathrm{~m}$ and water depths of $300-4,500 \mathrm{~m}$. During these tests, the highest $\mathrm{CE}$ achieved was CE-std of $86 \%$, or CE-var of $98 \%$. Under similar water and sea conditions, the DDIAHC reduces displacement by $50-60 \%$, or $75-84 \%$ variance of downhole tool motion during normal logging operations. The relative compensation efficiency (RCEs) values of the system during logging operations were generally higher than their corresponding CE values, in the range of RCE-std $=60-75 \%$ or RCE-var $=84-94 \%$. Such overall high CE performance is considered to be at least as good as or slightly better than the previous LWHC and SWHC systems deployed on the JOIDES Resolution.
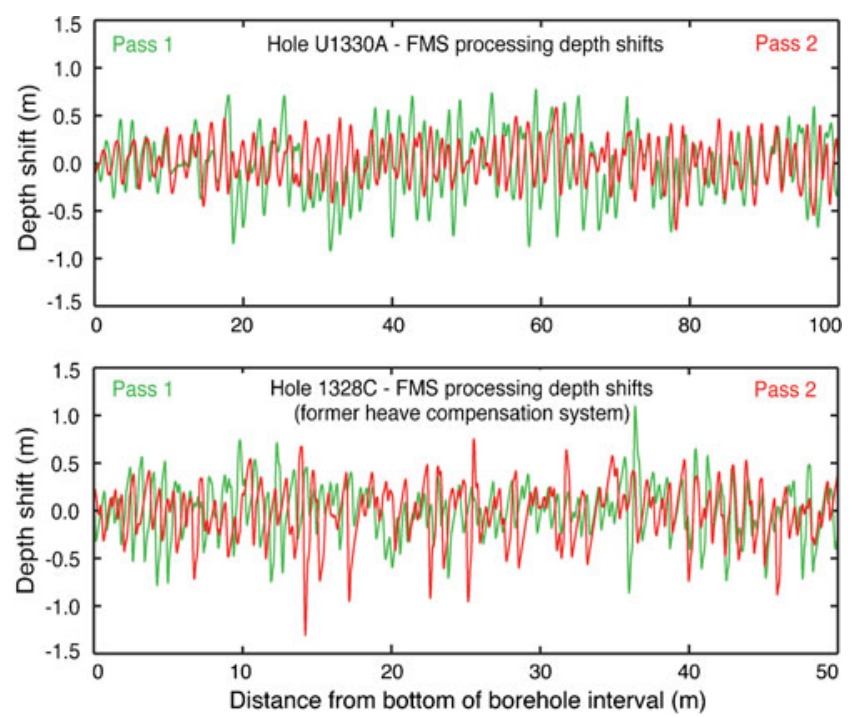

Fig. 10 Comparison of holes U1330A and 1328C FMS depth shifts during FMS image processing (with heave condition of $\pm 1-1.5 \mathrm{~m}$ for both logging operations) 
Fig. 11 Comparison of FMS images between passes in hole U1330A

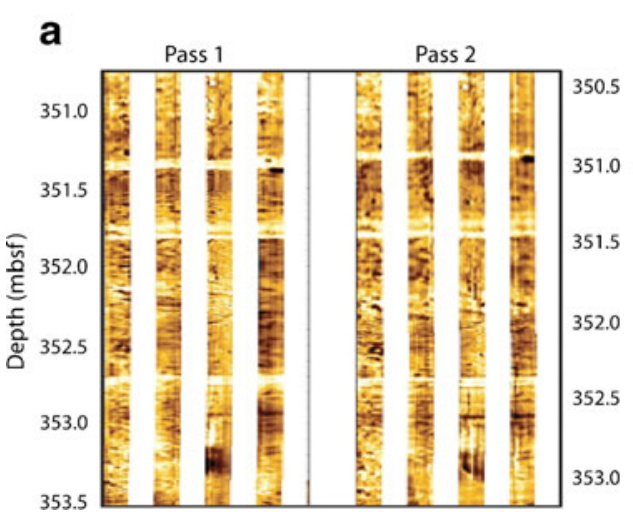

With optimum performance parameters, the DDI-AHC reduces downhole tool motion to less than $\pm 0.5 \mathrm{~m}$ (Figs. 8, 9 ), independently of water depth and sea state. Such low amounts of depth shifts can typically be corrected in postprocessing of logging data. Therefore, this represents a satisfactory level of compensation effectiveness provided by the DDI-AHC system for high-quality log data acquisition.

\section{Factors affecting CE}

In typical marine well logging environments, factors such as water depth, sea state, cable length, cable payload, logging direction, and speed often influence the effectiveness of wireline heave compensation. Based on this study (Table 2), however, water depth appears to have an insignificant effect on the overall performance of the DDI-AHC. The system performed in an optimum CE-std range of $65-80 \%$ in both shallow and deep waters with the same operating parameter settings. A similar observation was reported for the SWHC (Sarker et al. 2006). Table 2 illustrates that $\mathrm{CE}$ is generally independent of cable length and payload (including weight of tool strings). The natural frequencies of the compensation system and cable resonances at frequencies close to that of the ship heave (e.g., Dalmaijer and Kuijpers 2003) do not appear to have significant effects. Furthermore, the sea state and heave period do not appear to affect the overall performance of the heave compensator. Because the DDI-AHC receives its input driving function from ship heave, it is expected that heave-induced motion of the logging tool string adapts well to varying sea/heave conditions and compensates these effectively.

Logging direction and speed can affect its performance and are not currently incorporated into the compensation system. Based on the results in Table 2, logging down at high speeds of $1,000-1,200 \mathrm{~m} / \mathrm{h}$ in open holes reduces CE values by about $55-65 \%$; however, logging down, or up, at low speeds $(300-600 \mathrm{~m} / \mathrm{h})$ or logging up at high speed $(1,600 \mathrm{~m} / \mathrm{h})$ reduces $\mathrm{CE}$ values by about $15-20 \%$. Such large CE reductions during high-speed logging can be explained by cable slack and possible resonances of the logging cable when logging down. Other factors such as borehole shape, size, centralizers, and caliper arms of HLDS and FMS logging tools may also contribute to the higher CE values when logging at lower speed up/down or when logging up at higher speed. Such factors often cause erratic "stick-slip" motion of the downhole tool string that cannot be effectively compensated. Fortunately, at optimal logging speeds of $300-600 \mathrm{~m} / \mathrm{h}$, the overall impact of this on the quality of the logging data documenting the performance of the heave compensator is low.

\section{Future improvements}

Well-designed active heave compensation (AHC) systems have the potential to reduce over $90 \%$ heave motion (Wilde and Ormond 2009), as is the case for systems used on the JOIDES Resolution and other deep-water drilling vessels (Dalmaijer and Kuijpers 2003; IODP 2010). This study shows that the DDI-AHC system currently achieves CEs of $75-85 \%$, i.e., slightly lower than its potential, using input data only from the uphole ship motion and cable tension near the winch (i.e., cable-mounted tension device). Adding inputs of the downhole cable dynamics may improve DDIAHC operational performance to reach its full potential. Heave motion attenuation integrating active damping of cable vibration has been shown in simulation to achieve CEs as high as $99.5 \%$ in 3,000 m water depth with $\pm 2 \mathrm{~m}$ heave and a 60-ton payload (Yuan 2010). In the future, integration of downhole cable dynamics into the DDIAHC system could substantially improve compensation control and maximum CE. Thus, the current maximum reported in this study $\left(\mathrm{CE}_{\max }\right.$ of $\left.86 \%\right)$ could probably be increased by $10 \%$ or more. Computer modeling of the DDIAHC system integrating feedbacks from downhole cable tension may be a first step, followed by further system tests under marine logging conditions. Although technically complex, such downhole feedbacks on control of the surface DDI-AHC system could significantly improve the quality of $\log$ data acquired on the JOIDES Resolution or other deepwater drilling vessels. 


\section{Conclusions and recommendations}

The comprehensive assessment of the DDI-AHC system effectiveness was performed under well logging conditions typically encountered during IODP operations as well as open hole stationary tests. The effects of various operating parameters were quantitatively evaluated. The logging data recorded using the DDI-AHC were qualitatively analyzed for overall quality and reliability, including the repeatability of highresolution FMS images. The tests indicate that the DDIAHC system can provide a level of compensation efficiency of $50-85 \%$ for heave motion and heave variance attenuation, better than the previous LWHC and SWHC systems, and allows for high-quality log data acquisition in typical marine well logging environments. Additional input parameters to the DDI-AHC system such as downhole tool motion and cable tension could further improve control of the compensation efficiency by $10 \%$ or greater. Subsequent evaluation of the system performance using the WHCES should be used to confirm outcomes and the quality of the results.

Acknowledgments This research project was supported by the US National Science Foundation through contract \# OCE-0352500, IODP SODV subcontract JSC 5-03 and IODP subcontract JSC 4-03. We thank LEDO's Borehole Research Group (BRG) Deputy Director of Operations M. Reagan, IODP logging scientists L. Anderson, H. Evans, A. Fehr, G. Guerin, J. Inwood, A. Malinverno, S. Morgan, A. Slagle, and T. Williams, BRG engineers T. Hussein, S. Mrozewski, and W. Masterson, BRG IT group members T. Baker, C. Broglia, D. Quoidbach, and G. Sarker, and Schlumberger wireline services for their contribution and help in this project. We are also grateful to the scientific parties of IODP expeditions $320 \mathrm{~T}$ through 340 for their cooperation and assistance. Critical comments by two anonymous reviewers and suggestions by the editors have greatly improved the clarity of the paper. LDEO contribution number 7611.

\section{References}

Dalmaijer JW, Kuijpers MRL (2003) Heave compensations system for deep-water installation. GustoMSC Website. http://www. gustomsc.com/download/PaperDOT2003\%20AHC-Dal.pdf. Accessed 19 December 2010

Driscoll FR, Nahon M, Lueck RG (2000) A comparison of shipmounted and cage-mounted passive heave compensation systems. J Offshore Mech Arctic Eng 122:214-221

Goldberg D (1990) Test performance of the Ocean Drilling Program wireline heave motion compensator. Sci Drill 1:206-209

Guerin G (2009) Analysis of the performance of the previous wireline heave compensator from TAP data. Internal document. Lamont-Doherty Earth Observatory, Columbia University, Palisades, NY

Guerin G, Goldberg D (2002) Heave compensation and formation strength evaluation from downhole acceleration measurements while coring. Geo-Mar Lett 22:133-141. doi:10.1007/s00367002-0104-z

IODP (2010) IODP Website. http://www-odp.tamu.edu/publications/ tnotes/tn31/pdf/ahc.pdf. Accessed 12 June 2010

Meltser A (2005) A tale of two wireline heave compensators. Internal document. Lamont-Doherty Earth Observatory, Columbia University, Palisades, NY

Myers G, Gaillot P, Goldberg D (2001) Ship heave effects on ODP drilling dynamics: analysis of MWD data in the Nankai Trough. EOS Trans AGU 82(47), Fall Meeting Suppl, Abstract \# T41A0852

Sarker G, Myers G, Williams T, Goldberg D (2006) Comparison of heave motion compensation systems on Scientific Ocean Drilling Ship and their effects on wireline logging data. In: Proc Offshore Technology Conf, 1-4 May 2006, Houston, TX, paper 17916

Wilde B, Ormond J (2009) Subsea heave compensators. Intermoor Website. http://www.intermoor.com/download-technical-papers65? downloadid=217. Accessed 27 July 2012

Yuan Q (2010) Actively damped heave compensation (ADHC) system. In: Proc American Control Conf, 30 June-02 July 2010, Baltimore, MD, pp 1544-1549 